\title{
ЭВОЛЮЦИЯ ЛЮБВИ И ЕЕ ЖАНРОВЫЙ РЕПЕРТУАР КАК ПРЕДМЕТ РЕЧИ (НА ОСНОВЕ ИНТЕРПРЕТАЦИИ ПРОИЗВЕДЕНИЙ РУССКОЙ ХУДОЖЕСТВЕННОЙ ЛИТЕРАТУРЫ 19 ВЕКА)
}

\author{
Солмаз Кулиева
}

\section{EVOLUTION OF LOVE AND ITS GENRE REPERTOIRE AS A SUBJECT OF SPEECH (BASED ON THE INTERPRETATION OF WORKS RUSSIAN FICTION OF THE $19^{\text {TH }}$ CENTURY)}

\begin{abstract}
Solmaz Kulieva
Резюме: В статье представлена обзорная характеристика эволюции любви как коммуникативного феномена, семантизируются такие понятия, как любовь, влюбленность, страсть; делается вывод о том, что этапы любовного общения имеют особое жанровое наполнение и типичный набор ситуаций. Анализ жанров и ситуаций любовного общения в его развитии осуществляется на основе интерпретации произведений художественной литературы. Также в статье обосновывается актуальность изучения данного феномена со студентами-филологами на вузовских речеведческих занятиях.

Ключевые слова: любовь, эволюция любви, любовное общение, жанры любовного общения, произведения художественной литературы о любви.

Abstract: The article presents an overview of the evolution of love as a communicative phenomenon, semantics of such concepts as love, love, passion; it is concluded that the stages of love communication have a special genre content and a typical set of situations. The analysis of genres and situations of human communication in its development is based on the interpretation of works of fiction. The article also substantiates the relevance of studying this phenomenon with students of Philology at University speech studies.
\end{abstract}

Key words: love, evolution of love, love communication, genres of love communication, works of fiction about love.

DOI: $10.14712 / 9788076032088.15$

«Любовь бежит от mех, Кто гонится за нею, А тем, кто прочь бежит, Кидается на шею».

Вильям Шекспир

Умение любить - уникальная способность человека, которой он обучается с детства, впитывая любовь с молоком матери. Он учится любить родителей, домашних животных, природу, друзей. Но самые таинственные и трепетные эмоции человек испытывает, когда влюбляется в свою «половинку». Такая любовь переворачивает его внутренний мир, меняет 
сознание и подталкивает к различным поступкам. Наверное, именно поэтому теме любви посвящено творчество огромного количества деятелей искусства: писателей, живописцев, скульпторов, кинематографистов, театральных режиссеров, музыкантов и др.

Не меньшее значение приобретают и научные труды о любви. Однако в философии, этике и эстетике, психологии и речеведении любовь зачастую трактуется неодинаково. Даже в рамках одной науки определения любви могут быть самыми разнообразными. На наш взгляд, это связано с тем, что чувство, возникающее между влюбленными, всегда имеет индивидуальную природу и свою, очень личную траекторию развития. Именно поэтому в рамках статьи мы рассмотрим один из самых сложных и неизученных вопросов феномена любви - эволюцию любовных отношений на основе интерпретации произведений художественной литературы 19 века. Ни для кого не секрет, что художественная литература рассказывает своим читателям об уникальных любовных историях, которые являются художественно интерпретированными иллюстрациями современной писателю жизни. Это позволяет рассматривать данные истории как возможный образец поведения или как нравственный, психологический урок, который хочет преподнести художник слова своим современникам и потомкам. Писатели описывают любовные отношения героев, используя при этом различный жанровый репертуар, детально характеризуя мотивы поступков своих персонажей. В связи с этим мы предположили, что ситуации любовного общения на разных стадиях его развития (знакомства, влюбленности, страсти, любви-нежности, любви-дружбы) могут стать хорошим примером для участников реального общения. В то же время необходимо помнить, что детальный анализ любовных ситуаций, представленных в художественном тексте, важен для понимания идейного замысла писателя. Поэтому целью нашего научного интереса стало исследование феномена любви с точки зрения развития этого чувства и сопровождения всех его этапов значимыми для последних речевыми жанрами.

Изучив доступные нам источники (работы Т.В. Жеребило, Л.И. Скворцова, Д.Н. Ушакова, Э. 3. Фромма), мы пришли к выводу, что любовь в науке зачастую определяется как чувство привязанности к кому-либо или чему-либо, которое заставляет совершать поступки, ранее несвойственные человеку.

При этом в разных науках понятие любви дополняется некоторыми аспектами. Обратимся к их краткому обзору. Так, с точки зрения этики, любовь основана на идеализации образа конкретного человека и признании его ценности. Любовь - это чувство, которое человек испытывает сам, без какого-либо принуждения. В любовных отношениях индивид стремится к «обретению мира во всем его богатстве» (Словарь по этике 1989, 164-165). Если же рассматривать данный феномен с точки зрения эстетики, то наука о прекрасном говорит о любви как о способности человека видеть в объекте своей симпатии только прекрасное и неповторимое (Бычков 2004, 10).

Что касается философии, то известный ученый Эрих Фромм предлагает классификацию любви в зависимости от ее объекта и субъекта, а также содержания и целей выражения чувств. Он выделяет:

а) братскую любовь, предполагающую заботу, ответственность и уважение по отношению к другому человеку;

б) материнскую любовь, когда один человек нуждается в помощи, а другой - её оказывает;

в) эротическую любовь, характеризующуюся половым влечением одного человека к другому; 
г) любовь к себе, основанную на заботе, уважении, ответственности и знании себя самого;

д) любовь к Богу (Фромм 2009).

Обобщая сказанное, следует отметить, что выдающийся мыслитель 20-ого века акцентирует внимание на том, что все разновидности любви, несмотря на объект ее приложения и цели, предполагают ответственность и заботу об объекте симпатии.

При этом вопросу развития любовных отношений героев, объединяемых эротической любовью, следуя терминологии Э. Фромма, посвящено меньшее количество трудов (см. работы Ю.Л. Дмитриевой, Е.П. Ильина, О.Г. Прохоровой, Н.А. Тимофеева), особенно если речь идет о речевом воплощении этого чувства.

Однако на этапе теоретического анализа источников мы выяснили, что эволюция любви, т.е. естественный процесс ее развития (Ильин 2017), в основном включает в себя три явно выделяемых стадии: влюбленность, собственно любовь и страсть. Первую фазу называют «менее сложным чувством, нежели любовь, так как, кроме неё [влюбленности], последняя предполагает нежность, дружбу, привязанность, ревность и другие эмоции, производящие не передаваемое словами чувство любви» (Прохорова 2005, 54). Вторую стадию считают «...сильным, стойким, всеохватывающим чувством, определяющим направление мыслей и поступков человека» (Прохорова 2005, 54). Третья фаза - страсть - представляет собой особенно «интенсивное, напряженное и относительно устойчивое чувство субъекта» (Степанов 2013, 231249). Зачастую страсть занимает промежуточную позицию между влюбленностью и любовью, так как опыт наших наблюдений показал, что в начале взаимных отношений коммуниканты, как правило, ощущают обострение чувств, а следовательно, их страстное развитие - это логичный, но все-таки промежуточный этап между началом и длительным развитием отношений. Однако отметим, что чувство страсти, «подогреваемое» влюбленными партнерами, может возвращаться в их отношения по взаимному желанию, поэтому утверждать истинность позиции о том, что страсть - это второй этап любовных отношений, не имеющий возможности «вернуться», мы не будем.

При этом опыт анализа реальной речевой практики, а также содержания художественной литературы о любви позволил нам выделить еще две стадии развития отношений влюбленных - это знакомство и угасание любви. Очевидным является факт, что влюбленность, возникающая между партнерами, невозможна без первой личной встречи или приятно сложившегося дистантного общения коммуникантов (например, с помощью традиционных писем или современных диалогов в социальных сетях). Очарование любимым человеком нередко возникает именно на этапе знакомства, хотя нередки случаи, когда влюбленность появляется значительно позже, как, например, результат длительной дружбы коммуникантов. Однако в силу частности завязывания любовных отношений после первой встречи потенциальных влюбленных уместно выделить и знакомство как отдельную фазу развития любви (Ильин 2017).

При этом отношения героев-любовников по разным причинам нередко «сходят на нет». Зачастую это происходит из-за того, что одному из партнеров не уделяется должного внимания, происходит ущемление прав кого-либо из влюбленных, между любящими возникают неоднократные разногласия, незначительно или кардинально меняются их интересы и увлечения. И на этом этапе общения наблюдается иное речевое поведение его участников, включающее в себя модели действий и жанры, которые только усугубляют заканчивающиеся 
отношения (Прохорова 2005, Степанов 2013). Этот факт позволил нам выделить угасание любовных отношений в отдельный этап их развития.

Подводя промежуточный итог, отметим, что под эволюцией любви мы понимаем процесс развития взаимного чувства мужчины и женщины, начиная с этапов знакомства или влюбленности, которая может быть основана на первоначальной дружеской симпатии коммуникантов, и заканчивая различными вариантами их дальнейшего взаимодействия (до любви-дружбы, -страсти, или, напротив, разрыва отношений по разным причинам) (Ильин 2017). Каждой стадии таких отношений соответствует определенная палитра жанров любовного общения, под которыми мы понимаем особые типы высказываний, использующиеся любящими людьми в ситуациях любовной коммуникации. Отметим, что некоторые из этих жанров обладают конструктивным характером, то есть благоприятно влияют на развитие отношений коммуникантов, а часть жанров имеет негативное содержание, деструктивно влияющее на отношения влюбленных (Покровская 2014). Поясним, что оценку таких высказываний (речевых жанров) мы осуществляли на основе интерпретации известных произведений русской классики, так как среди доступных нам научных источников авторитетных работ, посвященных данному вопросу, мы не обнаружили.

Начнем характеристику речевых жанров, сопровождающих эволюцию любви, с комплимента. Так, в повести «Сорочинская ярмарка» Н.В. Гоголя этот жанр используется неоднократно, например:

- Вот я уже и не знаю, какого вам еще кушанья хочется, Аранасий Иванович! отвечала дородная красавица, притворяясь непонимающею.

- Разумеется, любви вашей, несравненная Хавронья Никифоровна! - шепотом произнес попович, держа в одной руке вареник, а другою обнимая широкий стан ее (Гоголь 2009, 14).

В данной ситуации герой обращается к комплименту для того, чтобы не только похвалить объект симпатии, но и расположить его к себе. Уточним, что комплименты частотны на всех стадиях любовного взаимодействия, за исключением этапа угасания любви (не всегда!), но самым востребованным жанром комплимент становится на стадии завязывания отношений между влюбленными (Покровская 2014).

Любовное признание - жанр любовного общения, который используется людьми для открытого выражения своих чувств к предмету симпатии (Покровская 2014). Образцы таких высказываний можно найти практически во всех произведениях художественной литературы, где есть любовный сюжет (произведения Ф.М. Достоевского, М.Ю. Лермонтова, А.С. Пушкина, И.С. Тургенева и др.). Однако признания в любви в диалоге героев не всегда получают взаимный ответ. Как правило, этот жанр используется одним или двумя участниками любовного общения на стадии четкого осознания любви к объекту симпатии, а следовательно, это уже более зрелый этап любовных отношений коммуникантов. Признаваться во взаимной любви они могут как на стадии любви-дружбы, нежности, так и на стадии страстного развития их чувств.

Так, например, в повести Ф. М. Достоевского «Белые ночи» используется не только признание в любви, но и объяснение этого чувства своему партнеру:

- Ну, что, что? - говорила она, перестав плакать и пристально смотря на меня, тогда как странное любопытство блистало в ее удивленных глазках, - что с вами?

- Это несбыточно, но я вас люблю, Настенька! вот что! Ну, теперь все сказано! сказал я, махнув рукой. - Теперь вы увидите, можете ли вы так говорить со мной, как сейчас говорили, можете ли вы, наконеи, слушать то, что я буду вам говорить... 
- Ну, что ж, что же? - перебила Настенька, - что ж из этого? Ну, я давно знала, что вы меня любите, но только мне все казалось, что вы меня так, просто, как-нибудь любите... Ах боже мой, боже мой! (Достоевский 2008, 29).

В приведенном примере целью главного героя, Мечтателя, является откровенный рассказ о своих искренних и настоящих чувствах к Настеньке. Адресант не только использует вербальные, но и пантомимические средства воздействия, позволяющие понять, что после объяснения в любви для мужчины наступило облегчение («Ну, теперь все сказано! - сказал я, махнув рукой...»).

Нередки на этих этапах и обещания влюбленных, которые предполагают, что то или иное действие будет обязательно совершено. Использование этого конструктивного жанра в любовном общении приводит к улучшению отношений между коммуникантами, дает надежду на дальнейшее их развитие. Так, в эпистолярном романе Ф.М. Достоевского «Бедные люди» Варенька Доброселова, до того как выходит замуж за нелюбимого ей Быкова, пишет письмо близкому для нее человеку - Макару Девушкину, где дает обещание: «... я буду вам писать, друг мой, я обещаюсь, но ведь один бог знает, что может случиться» (Достоевский 2015, 79). В данном случае обещание дается на стадии расставания героев, хотя их эмоциональная привязанность была столь же сильной, что и раньше. Как показывает анализ реальной и художественно интерпретированной речевой практики, жанр обещания может быть использован любящими людьми на разных стадиях развития их чувств и в самых разных ситуациях.

Литературные герои при этом могут не только объясняться в любви, давать обещания, делать комплименты, но и просить, а иногда даже и молить о чем-либо, то есть изъявлять определенное желание в надежде на его исполнение. Так, в рассказе А.П. Чехова «Ионыч» земский доктор Дмитрий Старцев, познакомившись с семьей Туркиных, влюбляется в Екатерину Ивановну, которую родители называют Котиком, и едет просить руки девушки, несмотря на то что она, назначив ему свидание на кладбище, не приходит: «... Любовь моя безгранична... Прошу, умоляю вас, - выговорил наконец Старцев, - будьте моей женой!» (Чехов 2008, 12). В данной ситуации просьба-мольба использована на этапе начала отношений героев, но более осознанно чувствует любовь к героине именно Старцев, а не Екатерина Ивановна.

Приведем еще один пример. В романе И.С. Тургенева "Дворянское гнездо» один из героев просит возлюбленную пообещать ему не торопиться с выбором спутника жизни: «Об одном прошу я вас, - промолвил он, возвращаясь к Лизе, - не решайтесь тотчас, подождите, подумайте о том, что я вам сказал. Если б даже вы не поверили мне, если б вы решились на брак по рассудку, - и в таком случае не за господина Паншина вам выходить: он не может быть вашим мужем... Не правда ли, вы обещаетесь мне не спешить?» (Тургенев 2008, 40).

Нередко жанрами любовного общения на разных стадиях его развития могут быть и жанры обиходно-этикетного взаимодействия (извинения, прощания, ласковые приветствия, пожелания, поздравления и др.) Репертуар таких жанров разнообразен и зависит от конкретных речевых ситуаций.

При этом наблюдения за реальной коммуникативной практикой, а также аспектный анализ художественных образцов позволили нам заключить, что на разных этапах любовной коммуникации можно выделить так называемые частотные жанры любовного общения. Так, например, на этапе влюбленности, т.е. начала любовных отношений, коммуниканты, как правило, используют такие жанры, как любовные признания, любовные послания, 
комплименты, любовные обещания, похвалу, благодарность за взаимные чувства, объяснения в любви и т.д.

На этапе зрелого развития чувств (собственно любви), сопровождаемого не только глубокой привязанностью влюбленных друг к другу, но и доверительностью общения, искренностью и бескорыстием в поступках, как правило, используются жанры конструктивного любовного общения: благодарность за совместное счастье, признания в искренности чувств, комплименты, разговоры по душам, положительные оценочные высказывания и др. Приведем пример.

В повести А.И. Куприна «Гранатовый браслет» использованы такие жанры любовной коммуникации, как комплимент, пожелание и благодарность за любовь: «Om глубины души благодарю Вас за то, что Вы были моей единственной радостью в жизни, единственным утешением, единой мыслью. Дай Бог Вам счастья, и пусть ничто временное и житейское не тревожит Вашу прекрасную душу. Целую Ваши руки» (Куприн 2008, 33).

Любовь к Вере Николаевне стала смыслом жизни Желткова, и даже в прощальном письме, фрагмент которого представлен выше, герой благодарен возлюбленной за то, что испытал великое чувство. В данном случае комплимент, сделанный Желтковым, говорит о том, что слова мужчины использованы с положительной экспрессией - с любовью и благодарностью.

На этапе страстного, бурного развития чувств влюбленные герои, даже если их история не взаимна, могут использовать клятвы, требования или мольбы о взаимной любви, клятвенные обещания и др. На этом этапе развития чувств коммуниканты могут сталкиваться с ситуациями ревности друг к другу, и зачастую в таких ситуациях общения возникают любовные конфликты, сопровождаемые взаимными упреками, обвинениями, необоснованными требованиями, замечаниями, сравнительными характеристиками (если речь идет о любовном треугольнике, например), мольбами о прощении или взаимном чувстве. Довольно часто страстное развитие чувств героев составляет кульминацию любовных отношений, которые могут сопровождаться спектром разных эмоций. Отсюда - использование не только конструктивных, но и деструктивных жанров любовной коммуникации (Ильин 2017, Покровская 2014). Приведем несколько примеров такого общения.

Так, в романе Л.Н. Толстого “Анна Каренина» представлен деструктивный жанр «обвинение». Благодаря этой тактике, Анна словесно выражает свое недовольство по поводу отношения к ней Вронского: "Для тебя это не имеет смысла, потому что до меня тебе никакого дела нет. Ты не хочешь понять моей жизни» (Толстой 2008, 580). Героиня, будучи импульсивной натурой, использует резкие реплики, указывая на вину любимого человека.

Еще одним жанром деструктивного общения, использованным в романе, является оскорбление. Нередко слова Вронского и умышленное намерение причинить боль героине ранят Анну, заставляя ее несколько раз прокручивать в голове слова любимого человека: «И действительно, он покраснел от досады и что-то сказал неприятное. Она не помнила, что она ответила ему, но только тут к чему-то он, очевидно с желанием тоже сделать ей больно, сказал:

- Мне неинтересно ваше пристрастие к этой девочке, это правда, потому что я вижу, что оно ненатурально.

Эта жестокость его, с которой он разрушал мир, с таким трудом построенный ею себе, чтобы переносить свою тяжелую жизнь, эта несправедливость его, с которой он обвинял ее в притворстве, в ненатуральности, взорвали ее. 
- Очень жалею, что одно грубое и материальное вам понятно и натурально, - сказала она и вышла из комнаты.

"Ненатурально», - вспомнила она вдруг более всего оскорбившее ее не столько слово, сколько намерение сделать ей больно» (Толстой 2008, 578).

К жанрам деструктивного любовного общения можно отнести и требование, высказывание, которое содержит в себе четкое указание на выполнение какого-либо действия и нередко используется в любовной коммуникации как категоричный и жесткий жанр. Например, в романе Ф.М. Достоевского «Идиот» Настасья Филипповна соглашается ехать с Рогожиным и настойчиво требует, чтобы он, не возражая, следовал за ней:

-Что же ты, Рогожин? Собирайся, едем!

- Едем! - заревел Рогожин, чуть не в исступлении от радости. - Ей вы... кругом... вина! Ух!.. (Достоевский 2008, 111).

Таким образом, подводя промежуточный итог, отметим, что репертуар жанров любовного общения героев художественной литературы довольно разнообразен, причем каждый из используемых жанров можно соотнести с определенным этапом развития отношений героев, в том числе в ситуациях разрыва отношений или невзаимной любви. Отметим, что невзаимная любовь так же включает в себя обозначенные нами этапы: от влюбленности до глубокой привязанности к объекту любви (хотя далеко не всегда такое чувство удовлетворяется со стороны адресата). Именно поэтому в качестве образцов для анализа мы выбирали не только ситуации взаимной любви героев, но и ситуации невзаимных любовных отношений.

При этом, на наш взгляд, анализ жанров любовной коммуникации на разных этапах ее развития (на основе анализа классических произведений художественной литературы) был бы неполным, если бы мы не провели констатирующий эксперимент среди своих сверстников (студентов-филологов) с целью узнать, как они понимают стадии развития любви и выделяют ли эти стадии в известных художественных текстах. В анкетировании приняли участие 40 человек студенты Новокузнецкого филиала-института Кемеровского государственного университета. Приведем образец разработанной и апробированной нами анкеты:

1. Как вы понимаете значения терминов «любовь» и «эволюция любви»? Сформулируйте, пожалуйста, их определения.

2. Какие этапы, на Ваш взгляд, включает в себя процесс эволюции любви? Назовите их в определенной последовательности и объясните свою позицию.

3. В каких произведениях русской / зарубежной литературы показана эволюция любви героев? Назовите сами произведения и их авторов.

4. С какой целью, на Ваш взгляд, известные мастера слова обращаются к изображению этого процесса? Свою точку зрения аргументируйте.

5. Прочитайте фрагменты из разных художественных текстов и назовите:

А) этап развития любовных отношений между героями;

б) жанр (-ы) их любовного общения.

Поясните свою позицию.

Фрагмент для анализа №1

- Я люблю вас, - повторил он, - и как я мог так долго обманываться, как я давно не догадался, что люблю вас!.. А вы?.. Наталья Алексеевна, скажите, вы?..

Наталья едва переводила дух.

- Вы видите, я пришла ююда, - проговорила она наконец. 
- Нет, скажите, вы любите меня?

- Мне кажется... да... - прошептала она (И.С. Тургенев. «Рудин»).

Фрагмент для анализа №2

- Вот я уже и не знаю, какого вам еще кушанья хочется, Афанасий Иванович! отвечала дородная красавица, притворяясь непонимающею.

- Разумеется, любви вашей, несравненная Хавронья Никифоровна! - шепотом произнес попович, держа в одной руке вареник, а другою обнимая широкий стан ее (Н.В. Гоголь. «Сорочинская ярмарка»).

6. Есть ли, на Ваш взгляд, определенная закономерность между эволюцией развития любовных отношений и жанрами любовного общения, которые используется в ней? Поясните свою позицию.

7. Необходимо ли, на Ваш взгляд, изучать речевые образцы любовного общения на разных его этапах на основе анализа произведений художественной литературы? Почему?

Кратко охарактеризуем полученные результаты. Анализ ответов на первый вопрос, связанный с характеристикой ключевых понятий исследования, показал, что большая часть респондентов $(71,4 \%)$ правильно трактует термины «любовь» и «эволюция любви». Приведем типичные ответы студентов: «Любовь - чувство глубокой эмоциональной привязанности, свойственное человеку. Эволюция любви - это процесс развития любовных отношений».

Во втором вопросе-задании необходимо было назвать этапы эволюции любви. 76,1\% опрошенных ответили верно, назвав не только влюбленность, страсть и любовь, но и симпатию, дружбу. В данном случае можно сделать следующий вывод: студенты понимают, что нередко чувство любви появляется у коммуникантов на этапе дружеского общения и возникшей на его основе симпатии, а затем оно может перерасти во влюбленность и любовь. Однако не всегда у любовных историй именно такой сценарий развития. Данный факт так же оказался для студентов очевидным.

В третьем задании респондентам необходимо было привести примеры из художественных текстов русских писателей, которые иллюстрировали бы разные стадии развития любви. Большая часть опрашиваемых $(85,7 \%)$ сумели ответить на вопрос и в качестве примеров привели такие произведения, как «Евгений Онегин» и «Капитанская дочка» А.С. Пушкина, «Отцы и дети» И.С. Тургенева, «Война и мир» Л.Н. Толстого, «Идиот» Ф.М. Достоевского. Названные тексты стали самыми популярными в числе приведенных вариантов.

Отвечая на четвертый вопрос, связанный с обозначением мотивов писателей, создающих любовные сюжеты, более $80 \%$ студентов отметили, что известные мастера слова обращаются к изображению процесса эволюции любви с целью показать изменение героя и то, как именно любовь влияет на личность человека. Зачастую речь шла о положительном преобразовании литературных персонажей, что может стать образцом, примером для читателей.

В пятом задании студентам необходимо было прочитать два фрагмента из художественных текстов и назвать этапы развития отношений героев, подтвердив свои ответы используемыми жанрами. В одном из фрагментов верно сумели определить влюбленность лишь $18 \%$ респондентов, остальные же либо неправильно назвали сам этап, либо перепутали жанры и этапы любви, либо не ответили на вопрос вовсе. Результаты анализа второго фрагмента оказались еще менее впечатляющими - 9\%. Это привело нас к выводу о том, что современные студенты-филологи, которые готовятся в будущем стать учителями-словесниками, плохо ориентируются в жанрах любовного общения и стадиях развития таких отношений, а 
следовательно, можно предположить, что в профессиональной практике они не смогут корректно оценить и охарактеризовать уникальные любовные сюжетные линии, созданные творческим воображением писателя, не смогут дать им правильную речевую оценку. Вполне возможно, что такие результаты обусловлены отсутствием у респондентов реальной любовной практики, но это в очередной раз утвердило нас в мысли об актуальности выбранной для исследования темы и необходимости ее целенаправленного изучения в рамках речеведческих занятий на факультете филологии.

Анализируя жанровый репертуар любовного общения героев тех же фрагментов, респонденты проявили большую осведомленность и правильно назвали используемые во фрагментах высказывания (признание в любви и комплимент).

Отвечая на шестой вопрос о том, есть ли закономерность между развитием любовных отношений и жанрами любовного общения, лишь $32 \%$ респондентов отметили, что такая закономерность есть, и попытались соотнести стадии и жанры любовной коммуникации.

Анализ ответов на седьмой вопрос показал, что большая часть респондентов $(85,7 \%)$ считают необходимым изучать речевые образцы любовного общения на разных его этапах, в том числе на основе анализа произведений художественной литературы, так как такой образец может помочь в реальной ситуации общения, став поучительным примером для современников. В результате, главным выводом нашей практической работы стало понимание того, что целенаправленное изучение сведений об эволюции развития любовных отношений и жанрах любовного общения, в том числе на основе интерпретации художественных текстов о любви, может усовершенствовать коммуникативные способности и литературоведческие умения студентов.

Подводя общие итоги научной работы, мы пришли к следующим выводам:

1. Классическая художественная литература является не только эстетическим, но и коммуникативным образцом для своих читателей, так как писатели-классики, создавая шедевры словесного искусства, зачастую опирались на собственный коммуникативный опыт. В результате, творчески преобразованные повествования о любви рассказывают современникам о самых разных вариантах развития любовных отношений между мужчиной и женщиной, становясь примером для анализа реального коммуникативного опыта.

2. Наш опыт наблюдений за реальной речевой практикой показал, что любовь при ее зарождении, в зрелом состоянии или в стадии завершения отношений любящих имеет разное жанровое наполнение, представляет собой различные модели речевого поведения любящих, и далеко не всегда эти речевые модели оказываются удачными. Нередко влюбленные попадают в сложные ситуации непонимания или неприятия друг друга, не могут достойно признаться друг другу в любви или, напротив, достойно, без обид завершить «остывшие» отношения. Однако анализ доступной нам научной литературы продемонстрировал, что эволюция любовных отношений, в том числе на основе интерпретации художественных образцов, в науке изучена недостаточно. Так, например, исследователи не уделяют должного внимания развитию любви в отношениях пары, не характеризуют жанровый репертуар любовной коммуникации, а также не определяют корректные модели речевого поведения коммуникантов в ситуации проблемного любовного общения.

При этом, изучив работы Т.В. Жеребило, Л.И. Скворцова, Э. З. Фромма и др., мы пришли к выводу, что любовь в науке зачастую определяется как чувство привязанности к кому-либо / чему-либо, подталкивающее человека на совершение ранее не свойственных ему поступков с целью продемонстрировать искренность отношения к объекту любви. Также мы определили, 
что любовь включает в себя пять стадий развития: знакомство, влюбленность, собственно любовь, страсть, «угасание» чувств (альтернативный вариант развития любовного общения). Для каждой стадии любовной коммуникации свойственны самые разнообразные жанры: признания в любви, клятвы, просьбы о прощении, оправдания, обвинения и др. Выявленные речевые жанры мы обнаружили в художественных текстах о любви, определив актуальность их использования на разных стадиях развития любовного общения в реальной речевой практике.

3. Разработанный и описанный выше констатирующий эксперимент подтвердил наши теоретические выводы и продемонстрировал, что в целом наши сверстники владеют общими представлениями о любовной коммуникации и стадиях ее развития (в том числе на основе анализа художественных образцов русской словесности), однако имеют сложное представление о ее жанрах. Именно поэтому целенаправленное изучение на речеведческих занятиях в вузе сведений об эволюции развития любовных отношений на основе интерпретации художественных текстов о любви, на наш взгляд, может усовершенствовать коммуникативные способности студентов, а также сформировать у них умения корректного литературоведческого анализа фрагментов из произведений классической художественной литературы.

\section{Использованная литература/ References}

\section{Печатные источники:}

БыЧкОВ, В.В. (2004): Эстетика. Москва : Гардарики, 2004. 305 с. ISBN 8-8297-0116-2.

гоголь, Н.В. (2009): Сорочинская ярмарка. Москва : Public Domain, 2009. 26 с.

ДМИТРИЕВА, Ю. Л.(2006): Эволюция героя в творчестве В. Максимова 1960-1970-х гг : специальность 10.01.01 «Русская литература» : диссертация на соискание ученой степени кандидата педагогических наук. Астрахань, 2006. 195 с.

ДОСтОЕВСКИЙ, Ф.М. (2015): Бедные люди. Москва : Public Domain, 2015. 81 c.

ДОстОЕВСКИЙ, Ф.М.(2008) : Белые ночи. Москва : Public Domain, 2008. 35 c. ISBN 978-5-271-04939-2. ДОСтОЕВСКИЙ, Ф. М. (2008) : Идиот. Москва : Public Domain, 2008. 387 с. ISBN: 5-17-021180-7.

ЖЕРЕБИЛО, Т. В. (2010): Словарь лингвистических терминов. Назрань : Пилигрим, 2010. 186 с. ISBN 978-598993-133-0.

ИльИН, Е.П. (2017) : Психология любви. Санкт-Петербург : Питер СПб, 2017. 336 с. ISBN 978-5-459-01640-6. КУПРИН, А. И. (2008) : Гранатовый браслет. Москва : Public Domain, 2008. 36 c. ISBN 978-5-699-22845-4.

ПОКРОВСКАЯ, О.О. (2014): Жанровый репертуар любовного общения в русской литературе XIX века как предмет риторического анализа на уроках словесности : специальность 44.03 .05 «Русский язык и литература» : выпускная квалификационная работа. Новокузнецк, 2014. 86 с.

ПРОХОРОВА, О. Г. (2005): Основы психологии семьи и семейного консультирования. Москва : Москва, 2005. 156 c. ISBN 9785534029314.

ПУШкинА, А. С. (2008): Капитанская дочка. Москва : Public Domain, 2008. 68 с. ISBN 978-5-17-036272-2.

СКВОРЦОВ, Л. И. (2009): Большой толковый словарь правильной русской речи. Москва : Оникс, 2009. 1103 c. ISBN 978-5-488-02271-3.

Словарь по этике (1989) / под ред. А. А. Гусейнова и И. С. Кона. Москва : Политиздат, 1989. С. 164-165. ISBN 5-250-01027-X.

СТЕПАНОВ, В. Е. (2013): Психология: учебник. Москва : Дашков и К', 2013. С. 231-233. ISBN 978-5-394-020636.

ТИМОФЕЕВ, Н. А. (2014): Эволюция героя в прозе А. П. Чехова 1890-1900-х годов : специальность 10.01.01 «Русская литература» : диссертация на соискание ученой степени кандидата педагогических наук Никита Анатольевич Тимофеев. Астрахань, 2014. 217 с.

толстой, Л. Н. (2008) : Анна Каренина. Москва : Public Domain, 2008. 644 с. ISBN: 978-5-04-107917-8.

ТУРГЕНЕВ, И.С. (2008): Дворянское гнездо. Public Domain, 2008. 112 с. ISBN 978-5-17-016131-7. 
ТУРГЕНЕВ, И.С. (2008) : Рудин. Москва : Public Domain, 2008. 78 с. ISBN 5-17-027075-5.

УШАКОВ, Д. Н. (2012): Толковый словарь современного русского языка: справочное издание. Москва : Аделант, 2012. С. 281. ISBN 978-5-93642-345-1.

ФРОММ, Э. 3. (2009): Искусство любить. Москва : АСТ-Москва, 2009. 65 с. ISBN 978-5-17-057714-9.

чЕXOB, А. П. (2008): Ионыч. Москва : Public Domain, 2008. 16 с. ISBN 978-5-17-031957-2.

\section{Онлайн-источники:}

КиберЛенинка : научная электронная библиотека. Эволюция героев: от «палеовенер» к постчеловеку [онлайн]. Режим доступа: https://cyberleninka.ru/ article/n/evolyutsiya-geroev-ot-paleovener-kpostcheloveku [дата обращения: 02.02.2020].

\section{Профиль автора:}

Солмаз Кулиева, студентка 3 курса факультета филологии Новокузнецкого института (филиала) ФГБОУ ВО «Кемеровский государственный университет»

Научный руководитель: Любовь Викторовна Гордеева, кандидат педагогических наук, доцент Научные интересы: коммуникативная культура педагога-филолога, речевая практика современников, жанры речи, теория и методика обучения русскому языку и литературе, школьное и вузовское филологическое образование.

e-mail: lyuba.gordeeva.85@mail.ru

Место работы: Новокузнецкий институт (филиал) ФГБОУ ВО «Кемеровский государственный университет», факультет филологии, кафедра русского языка и литературы; г. Новокузнецк, ул. Радищева, д. 34, кв. 21, индекс: 654086, Россия.

\section{Author's profile:}

Solmaz Kulieva, 3rd year student of the faculty of Philology of Novokuznetsk Institute (branch) Kemerovo state University

Scientific supervisor: Lyubov Viktorovna Gordeeva, candidate of pedagogical Sciences, associate Professor Research interests: communicative culture of a philologist, speech practice of contemporaries, genres of speech, theory and methods of teaching Russian language and literature, school and University philological education.

e-mail: lyuba.gordeeva.85@mail.ru

Place of work: Novokuznetsk Institute (branch) Kemerovo state University, faculty of Philology, Department of Russian language and literature; Novokuznetsk, 34 Radishcheva str., sq. 21, index: 654086, Russia. 